\title{
A Multimode Adaptive Pushover Procedure for Seismic Assessment of Integral Bridges
}

\author{
Ehsan Mohtashami and Ahmad Shooshtari \\ Department of Civil Engineering, Ferdowsi University of Mashhad, P.O. Box 91775-1111, Mashhad, Iran \\ Correspondence should be addressed to Ehsan Mohtashami; ehsan.mohtashami@stu-mail.um.ac.ir
}

Received 4 July 2013; Accepted 11 November 2013

Academic Editor: John Mander

Copyright (c) 2013 E. Mohtashami and A. Shooshtari. This is an open access article distributed under the Creative Commons Attribution License, which permits unrestricted use, distribution, and reproduction in any medium, provided the original work is properly cited.

\begin{abstract}
This paper presents a new adaptive pushover procedure to account for the effect of higher modes in order to accurately estimate the seismic response of bridges. The effect of higher modes is considered by introducing a minimum value for the total effective modal mass. The proposed method employs enough number of modes to ensure that the defined total effective modal mass participates in all increments of the pushover loading. An adaptive demand curve is also developed for assessment of the seismic demand. The efficiency and robustness of the proposed method are demonstrated by conducting a parametric study. The analysis includes 18 four-span integral bridges with various heights of piers. The inelastic response history analysis is employed as reference solution in this study. Numerical results indicate excellent accuracy of the proposed method in assessment of the seismic response. For most bridges investigated in this study, the difference between the estimated response of the proposed method and the inelastic response history analysis is less than $25 \%$ for displacements and $10 \%$ for internal forces. This indicates a very good accuracy compared to available pushover procedures in the literature. The proposed method is therefore recommended to be applied to the seismic performance evaluation of integral bridges for engineering applications.
\end{abstract}

\section{Introduction}

Over the past two decades, there has been an increasing attention to Nonlinear Static Procedures (NSPs) for the seismic assessment and evaluation of bridges. In these methods, a pushover analysis is carried out to estimate the inelastic capacity of the structure as well as its response to different levels of the seismic demand. The NSPs have the simplicity of the linear static methods and the accuracy of the nonlinear dynamic analyses. Therefore, they have become standard tools for the analysis of bridges in many seismic codes and guidelines such as EC8-2 [1] and Caltrans [2]. However, the principles of the NSPs are originally developed for buildings. It has been indicated by Isaković and Fischinger [3] that there are major differences between the structural system and the seismic response of buildings and bridges, particularly when the response of a bridge is analyzed in transverse direction. Therefore, the application of NSPs should be modified and adjusted for bridges.
The NSPs for the seismic assessment of bridges are generally based on two classic pushover procedures: the capacity spectrum method (CSM) [4] and the inelastic demand spectrum method also known as the N2 method [5]. Both methods consider a single mode and keep the shape of the pushover load distribution constant during the analysis. To overcome these deficiencies, several approaches have been proposed such as Modal Adaptive Nonlinear Static Procedure (MANSP) [6, 7] and Incremental Response Spectrum Analysis (IRSA) [8]. In these methods, the effect of higher modes is included in the analysis and the pushover load is considered a function of the updated modal characteristics of the structure.

In order to improve the efficiency of adaptive pushover methods for bridges, various studies have been conducted. Isaković and Fischinger [3] employed MANSP and IRSA methods and investigated the effect of higher modes in the seismic assessment of continuous-deck viaducts. Both 
MANSP and IRSA performed well for regular bridges. However, the accuracy of these methods was reported to decrease as the irregularity of the bridge increases. Casarotti and Pinho [9] developed a displacement-based procedure called Adaptive Capacity Spectrum Method (ACSM). This approach was shown to provide satisfactory predictions in terms of displacements and moments. Pinho et al. [10] employed four pushover procedures and conducted a parametric study for the seismic assessment of 14 continuous-span bridges. They concluded that the accuracy of pushover methods is generally acceptable. However, the dispersion of results was reported to be high for irregular bridges. Therefore, finding a more reliable method requires further investigation.

The main contribution of this paper is to present a refined multimode adaptive capacity spectrum approach in order to enhance the accuracy and reliability of NSPs in the seismic assessment of bridges. To do this, two improvements have been made in estimating the seismic capacity and demand. First, the capability to identify and include important higher modes in the pushover analysis is provided. This is done by introducing a minimum value for the total effective modal mass. The adequate number of modes is then included to ensure that the defined total effective modal mass participates in all increments of the pushover loading. In other words, the proposed method is able to incorporate variable number of modes in the analysis. Second, an adaptive demand curve is developed based on consecutive updating of the seismic demand. The derived adaptive demand curve is then intersected by the adaptive capacity curve to determine the performance point of the structure. To the best of authors' knowledge, the idea of using an adaptive scheme of both capacity and demand curves in the process of seismic assessment is novel and has not been presented yet. The formulation of the proposed method for obtaining the capacity curve of the structure is similar to ACSM [9]. However, the proposed method is basically a force-based pushover procedure while the ACSM is a displacement-based approach. Unlike ACSM, the number of the participating modes is not assumed fixed in the proposed method. Moreover, the capacity and demand curves are updated step by step and their intersection is checked in each increment for detection of the performance point. This provides a more straightforward procedure compared to ACSM in which the capacity curve is first obtained and the seismic demand is then applied in an iterative procedure to determine the performance point.

The paper is organized as follows. Section 2 presents the proposed assessment methodology as well as the new improvements implemented in the procedure. To evaluate the accuracy and efficiency of the proposed procedure, a parametric study is conducted in Section 3. Section 4 presents the numerical results of the parametric study and discusses the suitability and adequacy of the proposed method. Section 5 highlights concluding remarks.

\section{The Proposed Seismic Assessment Method}

The proposed method is performed in the following main steps: (1) assessment of the capacity curve of the bridge by conducting a multimode adaptive pushover analysis, (2) estimation of the adaptive demand curve based on the updated overdamped elastic response spectrum of the given ground motion, (3) determination of the performance point, and (4) determination of displacements and internal forces of the bridge. Details of these steps are explained as follows.

2.1. Assessment of the Adaptive Capacity Curve. The first step of the proposed procedure is to perform a pushover analysis on the bridge. A fiber based distributed plasticity finite element program is implemented in OpenSees [11] for the seismic assessment of bridges. The following steps are performed at each increment of the pushover loading.

(i) Conduct an eigenvalue analysis to find mode shapes. The proposed method provides the option to define an arbitrary value for the total effective modal mass, $M_{\mathrm{eff}}$, to be participated in the pushover analysis. For instance, if the common value of $90 \%$ of the total mass of the structure is selected for $M_{\text {eff }}$, our computer code will include an adequate number of modes in the assembly of the pushover load such that at least $90 \%$ of the total mass of the structure participates in the analysis. Since the method is an incremental procedure, this check for $M_{\text {eff }}$ is repeated at each load increment. Therefore, the number of the participating modes and consequently the shape of the pushover load vector repeatedly vary during the analysis. As a result, the changes of modal characteristics due to gradual softening of all structural members are well captured and included in the pushover curve.

(ii) Assemble the incremental pushover load vector, $\left\{\Delta P_{i}\right\}$, as

$$
\begin{gathered}
\left\{\Delta P_{i}\right\}=\Delta V_{\text {base }}\left\{\bar{F}_{i}\right\}, \\
\bar{F}_{i}=\frac{F_{i}}{\sum_{i} F_{i}}, \quad F_{i}=\sqrt{\sum_{j=1}^{m} F_{i j}^{2}},
\end{gathered}
$$

where $\Delta V_{\text {base }}$ is increment of the base shear defined at the beginning of the analysis, $\bar{F}_{i}$ is the normalized modal force at $i$ th degree of freedom (DOF), $F_{i}$ is the resultant modal force applied at DOF $i$ based on the Square-Root-of-Sumof-Squares (SRSS) combination rule, $m$ is the number of the participating modes, and $F_{i j}$ is the modal force of DOF $i$ at mode $j$ obtained as

$$
F_{i j}=\Gamma_{j} S_{a, j} m_{i} \Phi_{i j}, \quad \Gamma_{j}=\frac{\sum_{i} m_{i} \Phi_{i j}}{\sum_{i} m_{i} \Phi_{i j}^{2}},
$$

where $m_{i}$ is the mass of the $i$ th DOF, $\Phi_{i j}$ is the mode shape of DOF $i$ at mode $j, \Gamma_{j}$ is the modal participation factor of mode $j$, and $S_{a, j}$ is the spectral pseudo-acceleration of mode $j$ determined from the updated overdamped elastic response spectrum of the given input motion. The procedure for determining this spectrum will be explained in Section 2.2.

(iii) Perform an incremental-iterative analysis by employing the Newton-Raphson numerical method [12] as

$$
\left[K_{T}\right]\left\{\Delta D_{i}\right\}=\left\{\Delta P_{i}\right\},
$$




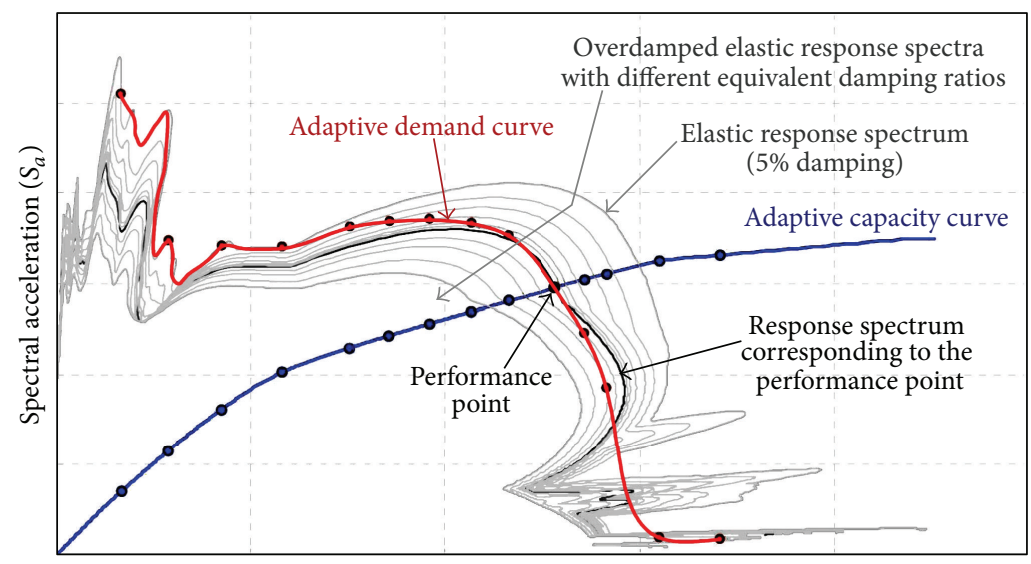

Spectral displacement $\left(S_{d}\right)$

FIGURE 1: The proposed procedure for detection of the performance point.

where $\{\Delta D\}$ is the incremental displacement vector of the bridge and $\left[K_{T}\right]$ is the tangent stiffness of the structure including geometrical and material nonlinearity.

(iv) Derive the adaptive capacity curve of the equivalent single-degree-of-freedom system by calculating the equivalent displacement $S_{d \text {,cap }}$ and the equivalent acceleration $S_{a \text {,cap }}$. These values are calculated in $k$ th step of the analysis as [9]

$$
\begin{gathered}
\left(S_{d, \text { cap }}\right)_{k}=\frac{\sum_{i} m_{i} \Delta_{i, k}^{2}}{\sum_{i} m_{i} \Delta_{i, k}}, \\
\left(S_{a, \text { cap }}\right)_{k}=\frac{\sum_{i} m_{i} \Delta_{i, k}^{2}}{\left(\sum_{i} m_{i} \Delta_{i, k}\right)^{2}} \frac{V_{\text {base }, k}}{g},
\end{gathered}
$$

where $g$ is the gravity, $V_{\text {base, } k}$ is the total base shear of the structure at step $k$, and $\Delta_{i, k}$ is the displacement of the mass $m_{i}$ at step $k$. Note that the equivalent displacement and acceleration of the structure do not refer to a specific physical location of the bridge and are updated based on the deformed shape of the structure.

2.2. Estimation of the Adaptive Demand Curve. At each step of the proposed procedure, the response spectrum of the ground motion is updated to match the current state of the structure. To do this, the equivalent damping of the structure is determined at each load step by the damping-ductility relationship of the Takeda degrading stiffness hysteretic response [13] as

$$
\xi_{\mathrm{eq}}=\xi_{0}+\frac{1}{\pi}\left[1-\frac{1-r}{\sqrt{\mu_{\mathrm{eq}}}}-r \sqrt{\mu_{\mathrm{eq}}}\right],
$$

where $\xi_{0}$ is the viscous damping of the bridge which is assumed as $5 \%$ of the critical damping, and $r$ represents the postyield to preyield stiffness ratio and is assumed to be 0.05 [14]. The equivalent ductility of the structure, $\mu_{\mathrm{eq}}$, is defined as the average ductility of all lateral resistant members, weighted by the shear force of each member. The reason is that the overall ductility of the structure is related to both ductility and stiffness of the members that contribute to the lateral resistance. The equivalent ductility of the bridge is then calculated as

$$
\left(\mu_{\mathrm{eq}}\right)_{k}=\frac{\sum_{i=1}^{n_{\mathrm{pier}}}\left(V_{k}^{\mathrm{pier}, i} \cdot \mu_{k}^{\mathrm{pier}, i}\right)+\sum_{j=1}^{2}\left(V_{k}^{\mathrm{abt}, j} \cdot \mu_{k}^{\mathrm{abt}, j}\right)}{V_{\text {base }, k}},
$$

where $\mu_{k}^{\text {pier, } i}$ and $\mu_{k}^{\text {abt, } j}$ are the displacement ductility of pier $i$ and abutment $j$ at step $k . V_{k}^{\text {pier, } i}$ and $V_{k}^{\text {abt, } j}$ are the shear force of pier $i$ and abutment $j$ at $k$ th step of the analysis. The term $\mu_{k}^{\mathrm{abt}, j}$ accounts for the effect of the soilabutment interaction which is explained in Section 3.2.

2.3. Determination of the Performance Point. In each analysis increment, the adaptive capacity curve is compared with the adaptive demand curve for detection of the performance point (see Figure 1). In initial steps of the analysis, the structure is elastic and the demand curve proceeds on the elastic response spectrum. When the first structural member starts to yield, the equivalent damping of the structure begins to increase according to (5) and (6). The demand curve is then shifted from the elastic spectrum to the derived spectrum. As yielding spreads within the structure, the demand curve is shifted from the spectrum of the previous step to the spectrum of the new step. When an intersection point is detected, it is saved in an output file as a potential performance point. However, the analysis continues because more than one intersection between the capacity and demand curves may be found [9]. The analysis stops when an ultimate limit state is met. Ultimate limit states are considered to occur either when the structure fails to resist the pushover load or when the columns reach a drift limit of 3\% [15].

2.4. Determination of the Structural Response. Once the performance point is detected, the structural response can be determined in terms of displacements and forces. The 


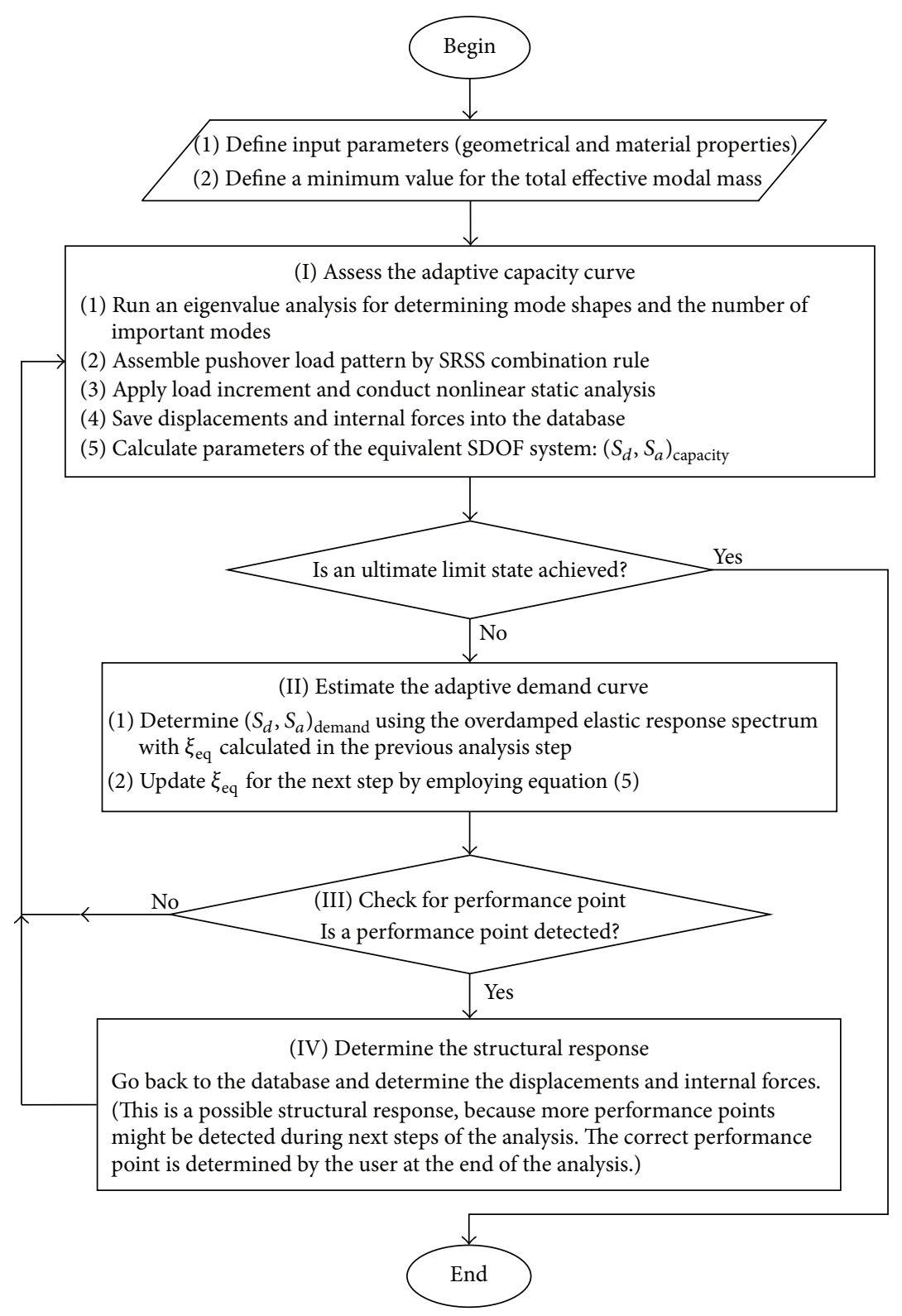

FIGURE 2: Flowchart of the proposed seismic assessment procedure.

flowchart of the proposed procedure is schematically summarized in Figure 2. To evaluate the efficiency of the proposed method, a parametric study is conducted in the next section.

\section{Description of the Parametric Study}

The parametric study consists of 180-meter long four-span integral bridges supported on pile foundations. The bridges are primarily designed according to AASHTO LRFD Bridge Design Specifications [16] and Caltrans Seismic Design Criteria [2] for the purpose of this study. Structural details of the investigated bridges are illustrated in Figures 3(a)-3(e). In this study, eighteen bridges with different pier heights are considered. These bridges are denoted by Bijk where $i$, $j$, and $k$ are label numbers that indicate the height of left, middle, and right pier, respectively. The height of each pier can be 6,12 , or 18 meters which will be labeled 1,2 , and 3 , respectively. For instance, the bridge in Figure 3(a) is denoted by B123. A fiber-based distributed plasticity finite element program is implemented in OpenSees for the proposed seismic assessment method. The minimum total effective modal mass is defined as $90 \%$ of the total mass of the structure. Geometrical nonlinearity is taken into account for all structural elements. The potential of inelasticity is restricted to columns. Nonlinear Winkler springs are employed to represent the reaction of soil on piles and abutments. The accuracy of the proposed method is evaluated by inelastic response history analysis (IRHA). For each of the 18 bridges, the analysis is performed under 10 strong ground motions. 


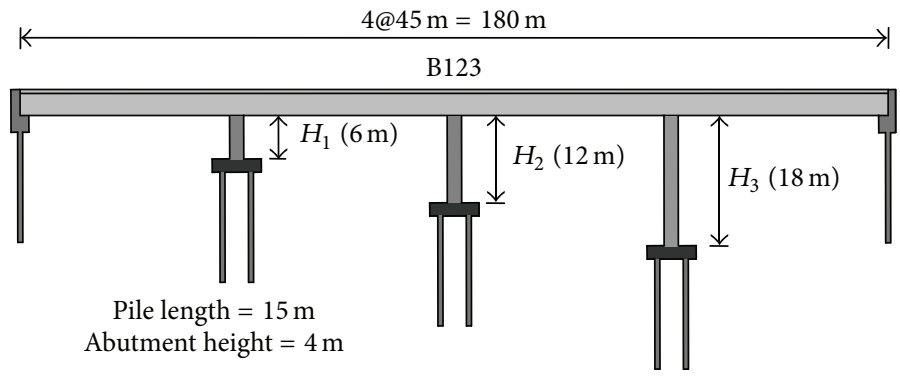

(a) Elevation view

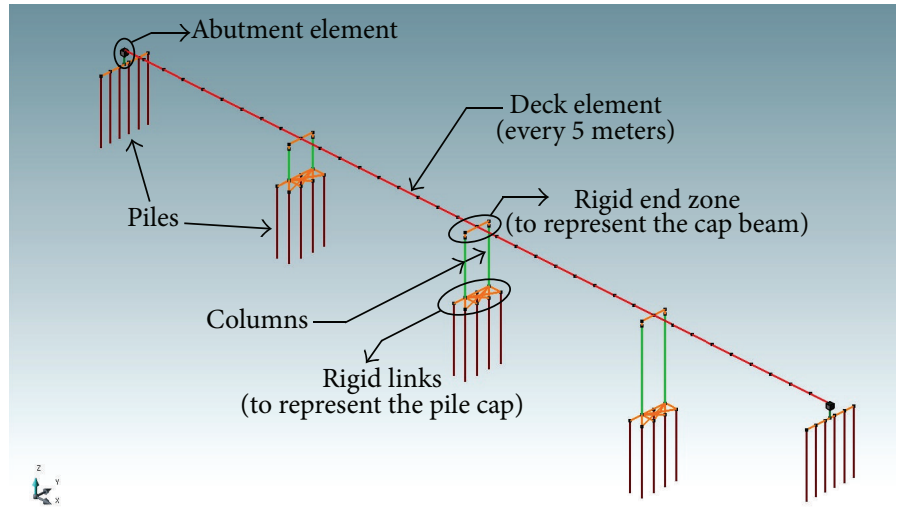

(b) 3D analytical model in OpenSees

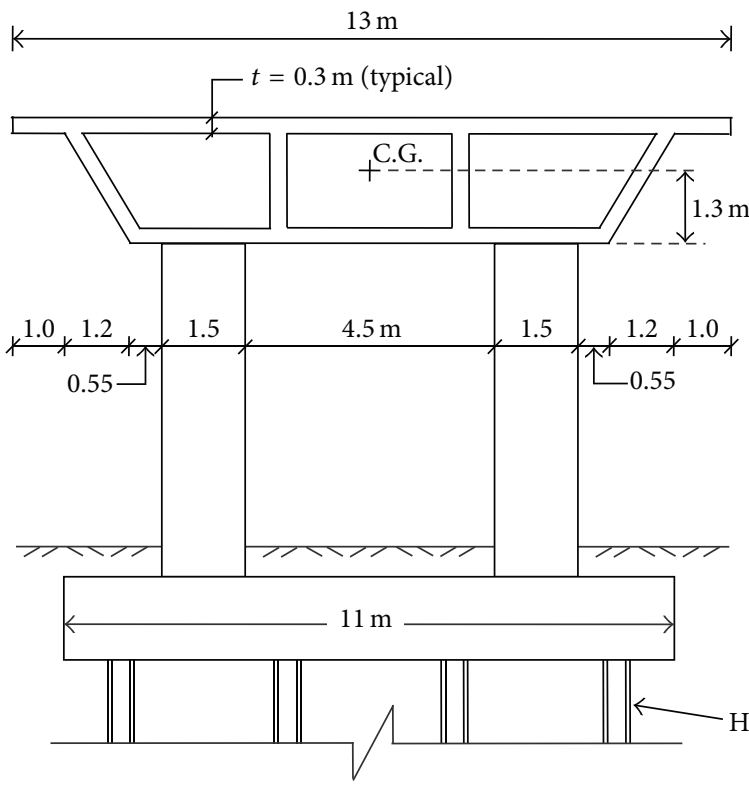

(c) Transverse section

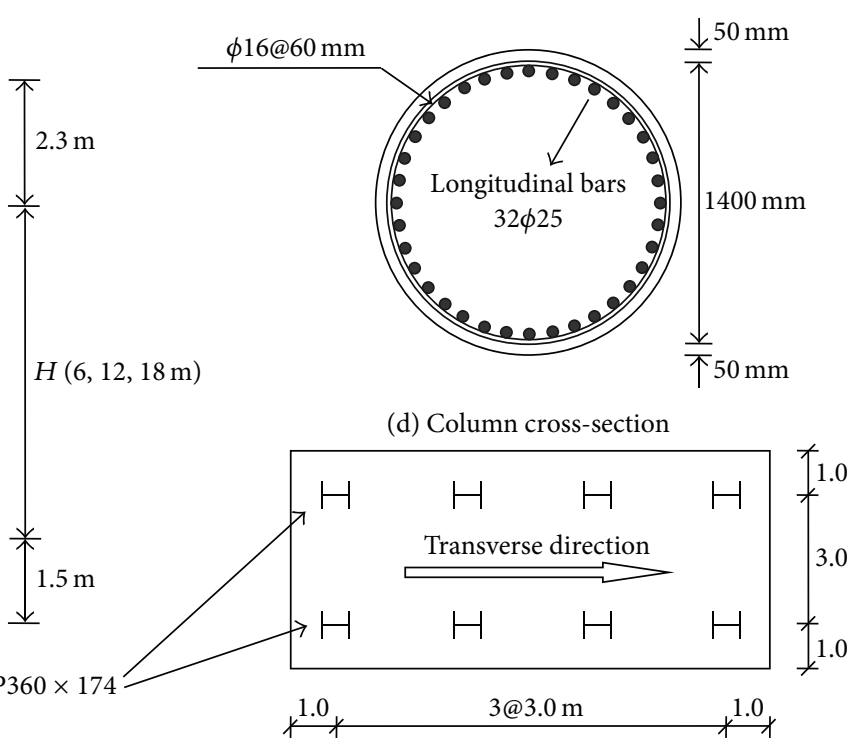

(e) Plan of the pile cap

FIGURE 3: Typical details of the investigated bridges.

This implies that a total number of 180 analyses have been carried out to evaluate the proposed method.

3.1. Structural Modeling. The three-dimensional (3D) finite element model of a typical simulated bridge is shown in Figure 3(b). The material of both superstructure and substructure is cast-in-place reinforced concrete. The concrete has Young modulus of $28 \mathrm{GPa}$ and compressive strength of $35 \mathrm{MPa}$. The constitutive law of the concrete is described by Mander's confined concrete model [17]. The modulus of elasticity of steel reinforcing bars is $200 \mathrm{GPa}$. The stress-strain relationship of steel is defined by Menegotto-Pinto model [18] with yield stress of $450 \mathrm{MPa}$. The total mass of the bridge includes the mass of the superstructure, cap beams, and half of piers. The total weights of the investigated bridges are in the range of 50100-50800 kN, depending on the height of their piers. The mass of each element is equally distributed at its end nodes. 


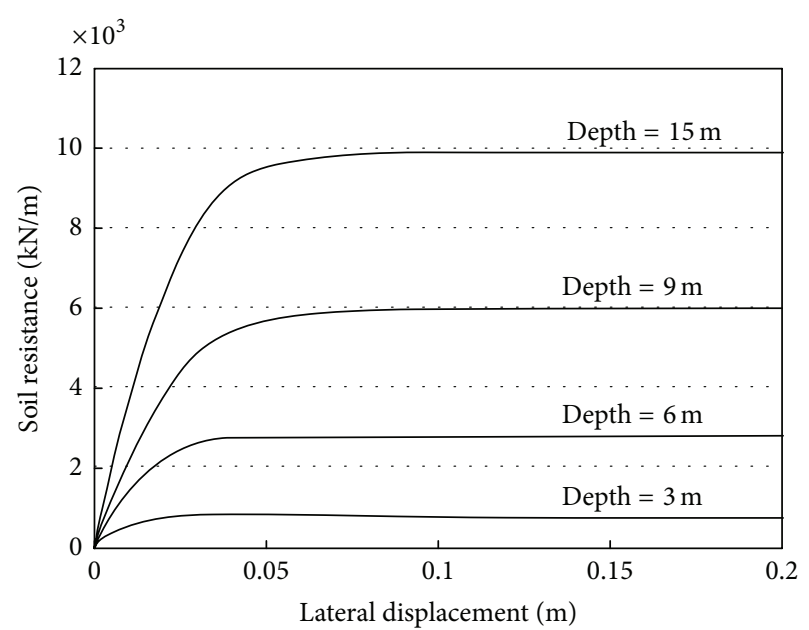

(a) Soil-pile interaction ( $p-y$ curves)

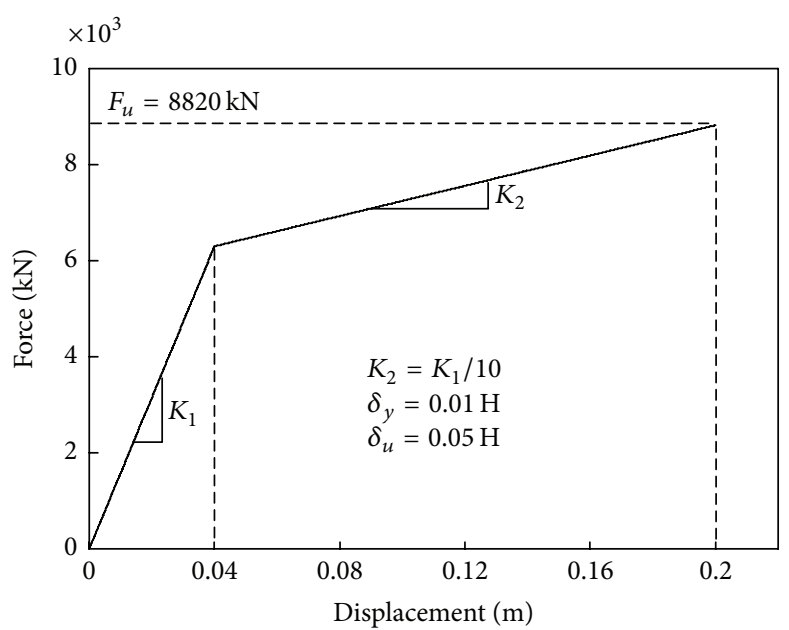

(b) Soil-wingwall-abutment interaction

FIgURE 4: Soil-structure interaction at abutments and foundation of piers.

The bridge deck is a multicell box girder as shown in Figure 3(c). The deck is modeled by 3D beam-column elements fully characterized by elastic sectional properties. A $50 \%$ reduction of elastic flexural rigidity (EI) and an $80 \%$ reduction of elastic torsional constant $(\mathrm{GJ})$ are considered according to recommendations given in Caltrans [2] for multicell box girder sections. The superstructure has monolithic connections to abutments and piers.

The bridge piers consist of two circular columns as illustrated in Figure 3(c). The cross-section of columns is depicted in Figure 3(d). A rigid end zone of $1.0 \mathrm{~m}$ is located at the top of columns to account for the offset between the top of columns and the structural nodes of the superstructure. The columns are modeled by 3D nonlinear beam-column elements with fiber cross-sections. The connection between columns and the pile cap is considered to provide full continuity. The pile cap is supported by 8 steel friction piles, as illustrated in Figure 3(e). The piles are 15 meters long and are modeled by 3D nonlinear beam-column elements. The soil stratum under the whole bridge is assumed to be stiff cohesionless sand with a unit weight of $18 \mathrm{kN} / \mathrm{m}^{3}$ and an internal friction angle of 40 degrees. All piles lie on the bedrock.

3.2. Soil-Structure Interaction. An important issue in the analysis of integral bridges is how to model the interaction of abutments, foundations, and piles with their surrounding soil. This interaction has significant influence on the seismic response and thus should be carefully included in the structural model of the bridge. In order to realistically model the soil-structure interaction, nonlinear springs are utilized to simulate the horizontal reaction of the soil around abutments and piles. Since the soil-structure interaction is not the main scope of this study, characteristics of soil springs are kept constant for all investigated bridges. The hyperbolic tangent curve recommended by the American Petroleum Institute [19] is employed for the lateral force-displacement relationship ( $p-y$ curve) of soil springs around piles. These springs are assigned along the length of piles under abutments and pier foundations. The $p-y$ curves at certain depths are plotted in Figure 4(a). The soil-abutment interaction in the transverse direction also includes the contribution of wingwalls. The effect of wingwalls is represented by a bilinear translational spring as shown in Figure 4(b). This spring is assigned to the top of the abutment in the transverse direction. The stiffness of this spring is determined by the shear capacity of one wingwall [20]. The initial stiffness $K_{1}$ and the postyield stiffness $K_{2}$ in Figure 4(b) are calculated based on elastic and ultimate shear capacities of the wingwall.

3.3. Ground Motion Records. The employed seismic excitation is defined by a set of ten natural near-fault ground motions from strong and major earthquakes around the world. Seven records are selected from the Pacific Earthquake Engineering Research Center strong-motion database [21] and three records from the Kyoshin strong-motion seismograph network [22]. The range of magnitude for the selected records is from 6.4 to 7.6, and the range of epicentral distance is from 2 to $22 \mathrm{~km}$. The characteristics of the input ground motions are summarized in Table 1 . The selected earthquake records cover a wide variety of near-fault ground motion parameters. In this study, the PGA of the records is scaled to $0.4 \mathrm{~g}$ in order to represent the design earthquake level. The effect of different intensity levels on the accuracy of the proposed method is later investigated in Section 4.4. The ground motions are applied in the transverse direction of the bridge.

3.4. Statistical Analysis. Results of the parametric study are presented in terms of various response parameters among which, deck displacements, pier base displacements, and column base moments are investigated here. In order to evaluate the accuracy of the proposed method, the response parameters are normalized to the response of IRHA for each input ground motion. This provides a good measure 
TABLE 1: List of the selected input ground motions.

\begin{tabular}{lcc}
\hline Earthquake* $^{*}$ & Station-component & PGA (g) \\
\hline Tabas, Iran (1979) & 9101 Tabas-NS & 0.852 \\
Loma Prieta, USA (1989) & 13 BRAN-NS & 0.501 \\
Northridge, USA (1994) & 24087-NS & 0.344 \\
Kobe, Japan (1995) & Nishi-Akashi-NS & 0.503 \\
Chi Chi, Taiwan (1999) & CHY101-NS & 0.440 \\
Duzce, Turkey (1999) & Duzce-NS & 0.535 \\
Bam, Iran (2003) & Bam-NS & 0.649 \\
Iwate, Japan (2008) & IWT010-NS & 0.223 \\
Shizuoka, Japan (2009) & SZO014-NS & 0.314 \\
Shizuoka, Japan (2011) & SZO011-NS & 0.511 \\
\hline
\end{tabular}

for evaluation of the proposed method since all quantities are normalized.

Due to random nature of earthquakes, any seismic response of a structure can be considered as a random variable. This response is a function of the input ground motion as well as the DOF at which it is computed. In order to properly characterize the response of the structure, the behavior of each response parameter has to be studied at different DOFs subjected to various ground motions. In other words, the input ground motion and the DOF should be statistically modeled. As a result, an arbitrary response parameter, say $R$, can be considered as a random variable. By $R_{i j}$, we mean the response parameter $R$ at the $i$ th DOF subjected to the $j$ th ground motion. To evaluate the accuracy of our proposed method, $R_{i j}$ is calculated by our nonlinear static procedure and then compared to the result of the IRHA as the reference solution. This is mathematically represented as

$$
e_{i j}=\frac{R_{i j}^{\mathrm{NSP}}-R_{i j}^{\mathrm{IRHA}}}{R_{i j}^{\mathrm{IRHA}}},
$$

where the superscripts NSP and IRHA denote the proposed nonlinear static procedure and the inelastic response history analysis, respectively. Note that we have selected the relative difference, $e_{i j}$ as the likelihood measure of our proposed method to the reference solution. If the proposed method estimates the seismic response exactly as the IRHA, $e_{i j}$ is equal to zero. The mean of the random variable $e$ is obtained as

$$
\bar{e}=\frac{1}{n_{i} \cdot n_{j}} \sum_{i=1}^{n_{i}} \sum_{j=1}^{n_{j}} e_{i j},
$$

where $n_{i}$ is the total number of DOFs at which the response parameter is computed and $n_{j}$ is the number of input ground motions applied to the bridge. The standard deviation of $e$ indicates the dispersion of the response predicted by the proposed method compared to the IRHA result. It is written as

$$
\sigma_{e}=\sqrt{\frac{1}{\left(n_{i} \cdot n_{j}\right)-1} \sum_{i=1}^{n_{i}} \sum_{j=1}^{n_{j}}\left[e_{i j}-\bar{e}\right]^{2}} .
$$

The necessary condition for accepting the accuracy of the proposed method is that the mean of the relative difference should be close to zero. This condition ensures that the proposed procedure is potentially able to properly predict the results obtained by the IRHA. The sufficient condition, on the other hand, is satisfied when the standard deviation of the relative difference is sufficiently small. This condition guarantees that the results estimated by the proposed method are always close to the IRHA results. Therefore, the proposed method is considered accurate if and only if both mean and standard deviation of the relative difference are sufficiently small.

Based on the computed standard deviation, it is useful to consider a confidence range for the relative difference as a measure of accuracy. The $95 \%$ confidence is a common value in probabilistic and reliability analysis of structures and is therefore accepted in this study. The 95\% confidence range for a normally distributed random variable $x$ is from $\bar{x}-$ $2 \sigma_{x}$ to $\bar{x}+2 \sigma_{x}$ where $\bar{x}$ and $\sigma_{x}$ denote the expected value and the standard deviation of $x$, respectively. If the dispersion of the relative difference is low, the $95 \%$ confidence range is small and the estimation of the response parameter is considered accurate. The normality of the relative difference can be verified by the nonparametric Kolmogorov-Smirnov (K-S) test [23]. This test is performed by the widely used statistical software SPSS. All relative differences for the response parameters of this study have successfully passed the K-S test and thus have been verified to follow the normal distribution. Numerical results of the parametric study are presented in the next section.

\section{Discussion on the Numerical Results}

The eighteen bridges considered in this study can be geometrically classified as regular and irregular based on the definition of the regularity index proposed by Calvi et al. [24] . According to the comprehensive study of Akbari and Maalek [25] on the regularity of bridges, the bridges B111, B121, B131, B222, B232, B323, and B333 of this study are identified as regular, and the other 11 bridges are irregular. The effect of regularity on the response of the proposed method will be investigated in Section 4.2. The accuracy of the proposed method is evaluated by the inelastic response history analysis having a $2 \%$ Rayleigh damping assigned to the two modes with the highest effective modal mass.

4.1. Results of the Statistical Analysis. Results of the statistical analysis of Section 3.4 are presented here. The mean and 95\% confidence range of the relative difference $e$ are presented in Figures 5, 6, and 7 for deck displacements, pier base displacements, and column base moments, respectively. The standard deviations of the relative difference $\left(\sigma_{e}\right)$ are shown in Figure 8. Results for each response parameter are discussed in detail as follows.

The selected DOFs for the deck displacement response are located at every 15 meters along the length of the bridge. This implies a total of 11 DOFs for this response parameter. Considering the 10 input ground motions of Table 1 , 


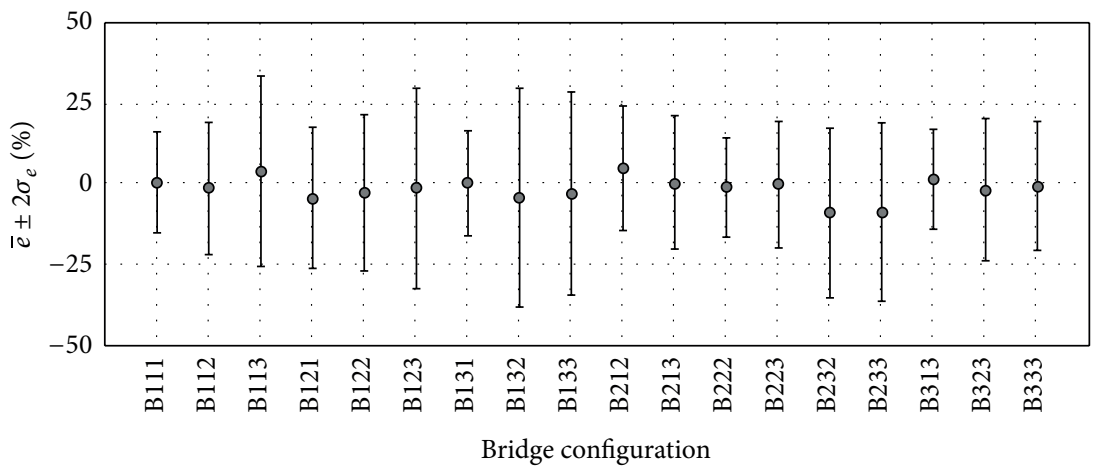

FIGURE 5: Mean and 95\% confidence range for deck displacements.

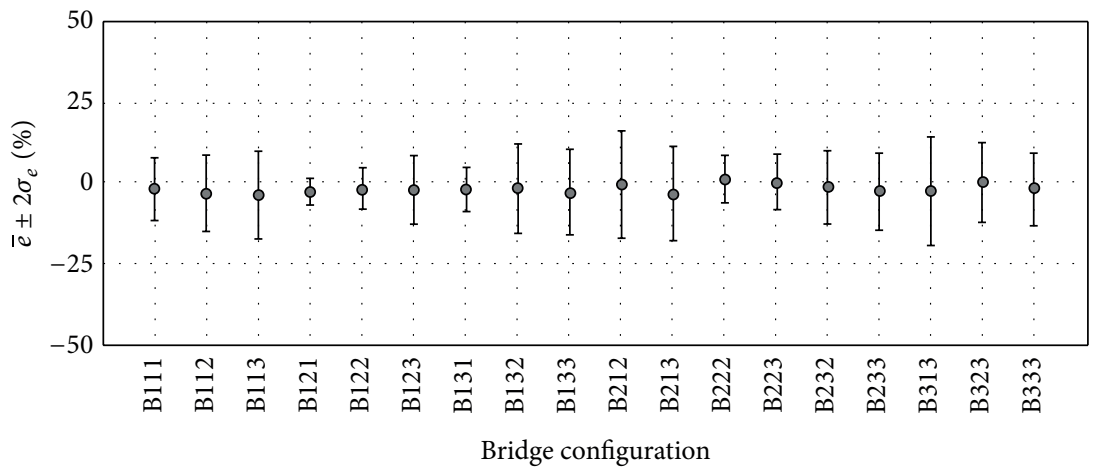

Figure 6: Mean and 95\% confidence range for pier base displacements and rotations.

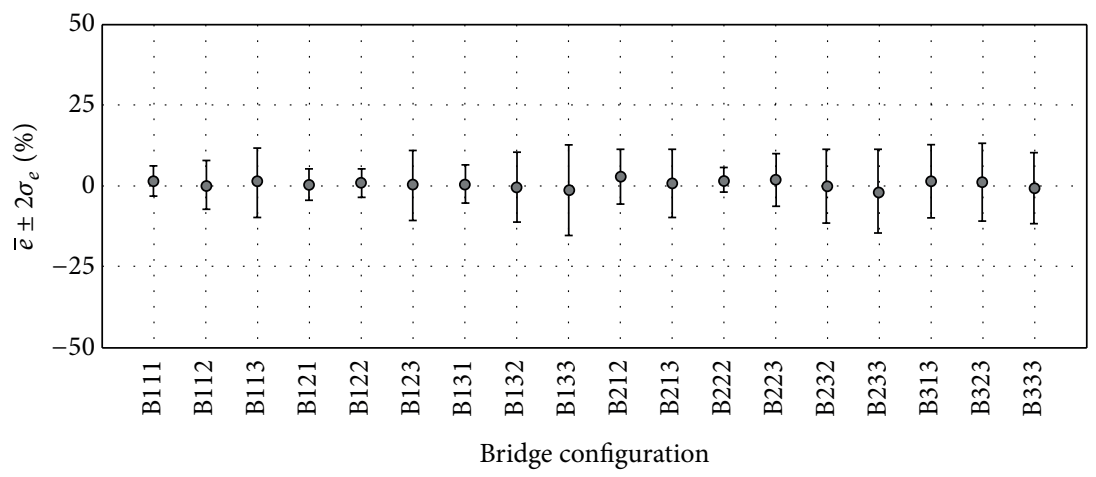

FIGURE 7: Mean and 95\% confidence range for column base moments.

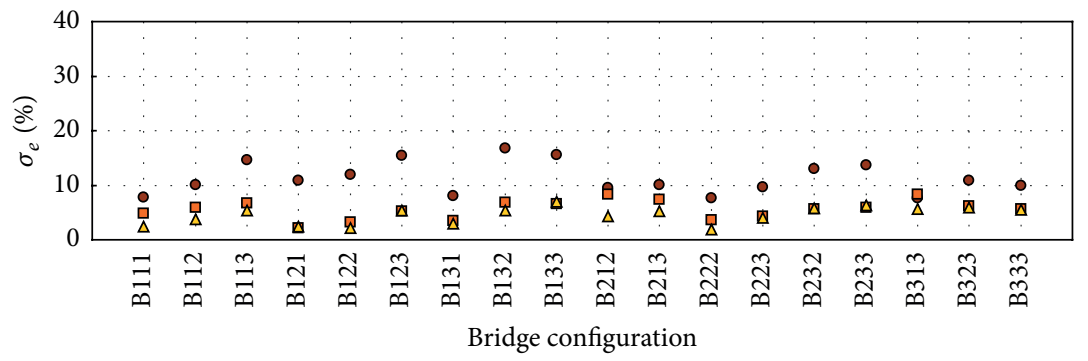

- Deck displacement pattern

- Base displacements and rotations

$\Delta$ Column base moments

FIGURE 8: Standard deviation of the bridge response parameters. 
a total number of 110 realizations are provided for the relative difference $e$. The K-S test shows that this sample follows the normal distribution very well. The mean, $\bar{e}$, ranges from $-8 \%$ to $+5 \%$ which indicates that the proposed method has the necessary condition to accurately estimate the displacements of the superstructure. With 95\% confidence, the relative difference for 12 bridges shown in Figure 5 is less than $25 \%$. This means that for two-thirds of the investigated bridges, the proposed method confidently estimates the deck displacements with less than $25 \%$ difference compared to the IRHA results. The standard deviation of the response obtained by the proposed method is in the range from $8 \%$ to $17 \%$. As reported by Pinho et al. [10], the standard deviation for deck displacements is up to $40 \%$ in different pushover procedures. Therefore, the proposed method satisfies the sufficient condition of accuracy for estimating the deck displacements. It can be concluded then that the proposed method estimates the deck displacement response with satisfactory accuracy.

The selected DOFs for the response of each pier base are the displacement in the transverse direction and the rotation about the longitudinal axis of the bridge. Therefore, 6 DOFs are selected for each bridge. Considering the 10 input ground motions, a total number of 60 realizations are included in the sample. The result of the K-S test indicates that the random variable $e$ follows the normal distribution. The mean, $\bar{e}$, ranges from $-4 \%$ to $+2 \%$ which indicates the excellent adequacy of the necessary condition. As can be seen in Figure 8, the standard deviation ranges from 2\% to $9 \%$. According to the results of Pinho et al. [10], the standard deviation is low enough to satisfy the sufficient condition of accuracy. It is then concluded that the proposed method excellently estimates the displacement response of the pier base.

For the column base moments, 6 DOFs corresponding to six columns of the bridge are considered. Employing the 10 ground motions of Table 1 , a total number of 60 realizations are obtained in the sample. The mean, $\bar{e}$, ranges from $-2 \%$ to $+3 \%$ which indicates that the proposed method provides the necessary condition excellently. As can be seen in Figure 7, the proposed method has confidently predicted column base moments in all the eighteen bridges with less than $15 \%$ difference compared to the IRHA results. The maximum standard deviation of the relative difference is $7 \%$ (see Figure 8). This indicates the remarkable accuracy of the proposed method. Pinho et al. [10] reported the standard deviation of the column shear force (and consequently the base moment) up to $20 \%$. Therefore, the standard deviation obtained by the proposed method well satisfies the sufficient condition of accuracy for estimating the column moment response. Therefore, it can be concluded that the proposed method estimates the column base moment response with desirable accuracy.

4.2. Effect of Bridge Regularity on the Results. The overall effect of bridge regularity on the response of the proposed method is investigated by evaluating the standard deviation of the random variable $e$ as shown in Table 2. The average
TABLE 2: Accuracy of the proposed method for regular and irregular bridges.

\begin{tabular}{|c|c|c|}
\hline \multirow{2}{*}{ Response parameter } & \multicolumn{2}{|c|}{ Average of standard deviation } \\
\hline & Regular bridges & Irregular bridges \\
\hline Deck displacements & $9.7 \%$ & $12.3 \%$ \\
\hline $\begin{array}{l}\text { Pier base displacements } \\
\text { and rotations }\end{array}$ & $4.5 \%$ & $6.3 \%$ \\
\hline Column base moments & $3.8 \%$ & $4.9 \%$ \\
\hline
\end{tabular}

standard deviation of the seven regular and the eleven irregular bridges is calculated and compared, for the selected response parameters. It is observed that the accuracy of the proposed method in estimating all three response parameters is slightly more reliable for regular bridges. However, this difference is small and the bridge regularity has negligible effect on the accuracy of the proposed procedure.

4.3. Case Study Results. In order to highlight the features of the proposed method, a case study is explained here. To maintain the generality of discussion, bridge B123 is considered because its piers have different heights and the symmetry does not affect its seismic response. The Northridge record (with the PGA scaled to $0.4 \mathrm{~g}$ ) is also selected among the records of Table 1. Figure 9 shows the variation of the pushover load pattern acting on the bridge deck. At the beginning of loading, the columns are elastic and their lateral stiffness is considerable. The bridge deck can therefore be considered as a multispan continuous beam in the transverse direction. The intensity of the pushover load in the middle of the bridge is higher than that in the regions near the abutments (see dash lines in Figure 9). As the loading increases, the columns start to yield and their stiffness degrades. Therefore, as seen in Figure 9(a), the intensity of the pushover load shifts from the middle of the bridge to its ends where more stiffness is provided by abutments. As the loading continues and more inelastic deformation is introduced in columns, more load shifts from the middle of the bridge towards abutments as shown in Figure 9(b). Gradually, the stiffness of abutments degrades and some load is redistributed from the regions near abutments back to the middle of the bridge, as can be seen in Figure 9(c). As the structure approaches the ultimate limit state, columns experience extensive inelastic deformations and their stiffness becomes very small. Therefore, the bridge deck behaves like a single-span beam supported by two abutments. At this point, only the first mode participates in the analysis and, consequently, the pushover load distribution resembles a parabolic shape as shown in Figure 9(d).

Table 3 shows modal characteristics of B123. It is observed that three modes have participated in the analysis. As columns start to yield consecutively, the first mode gradually tends to dominate the vibration of the bridge. The effect of the second mode is negligible, whereas the third mode with the modal mass ratio of about $20 \%$ significantly participates in the vibration of the bridge. The period of vibration 


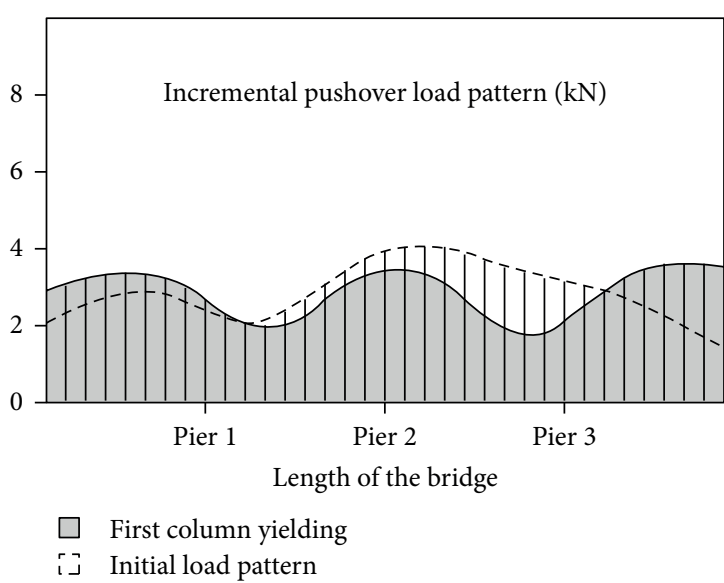

(a)

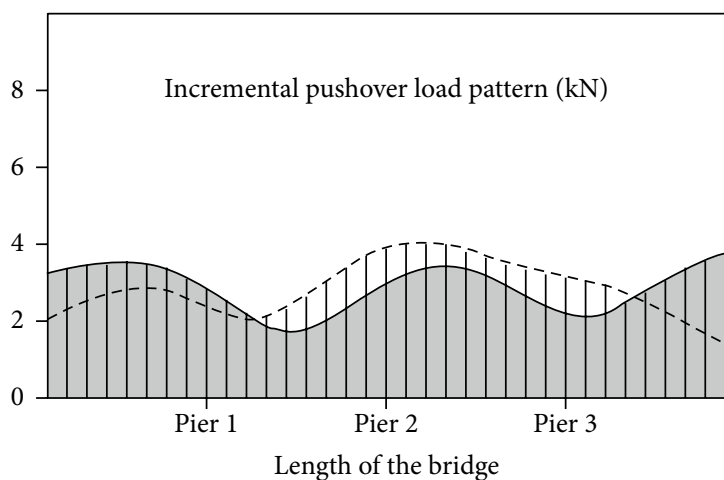

$\square \quad$ Third column yielding

[] Initial load pattern

(c)

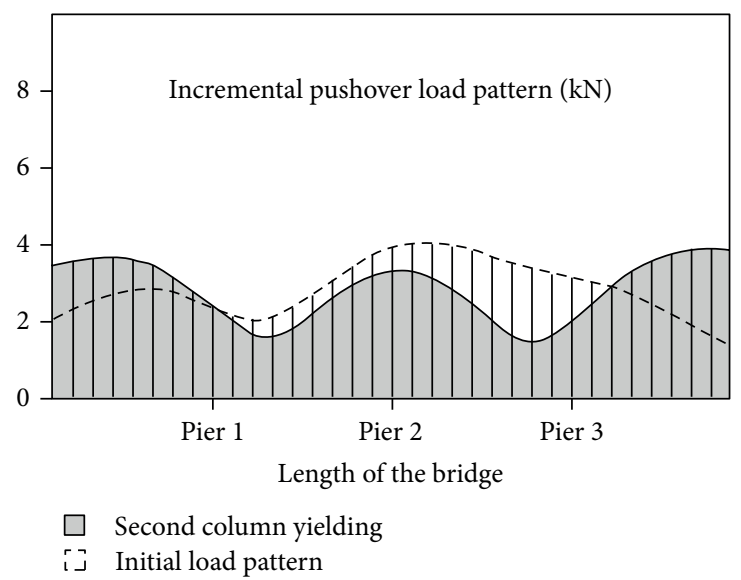

(b)

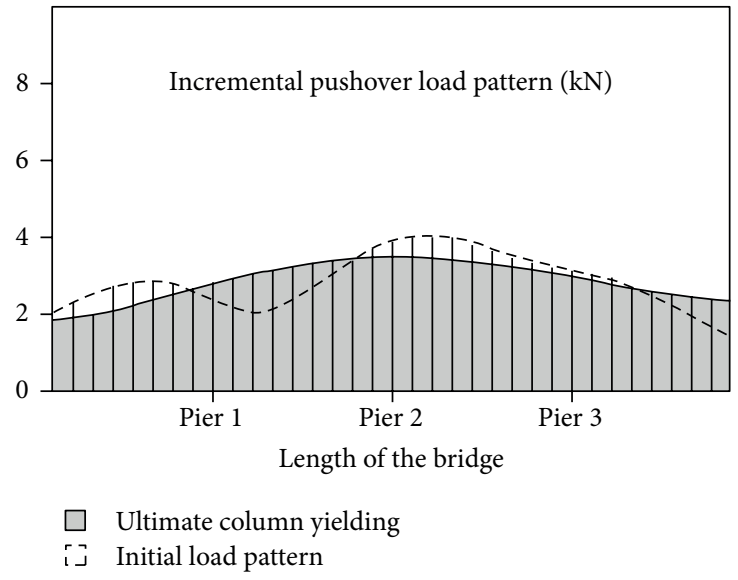

(d)

Figure 9: Variation of the pushover load pattern during the analysis (for B123).

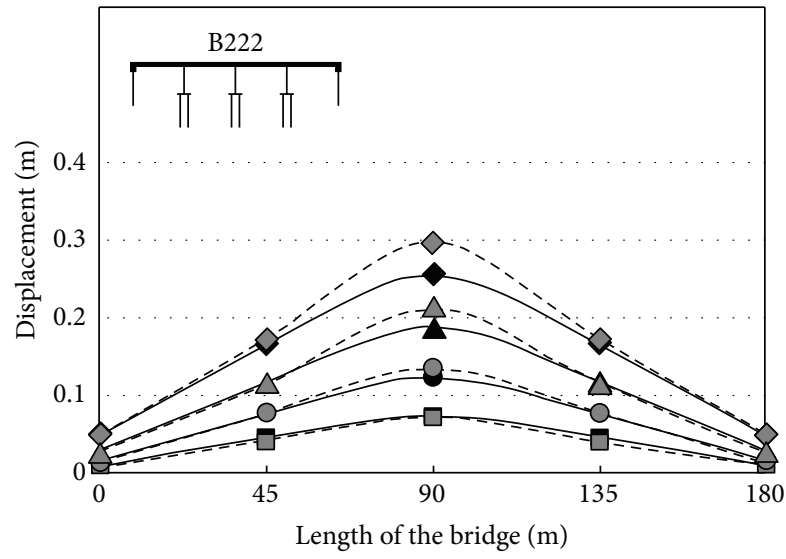

(a)

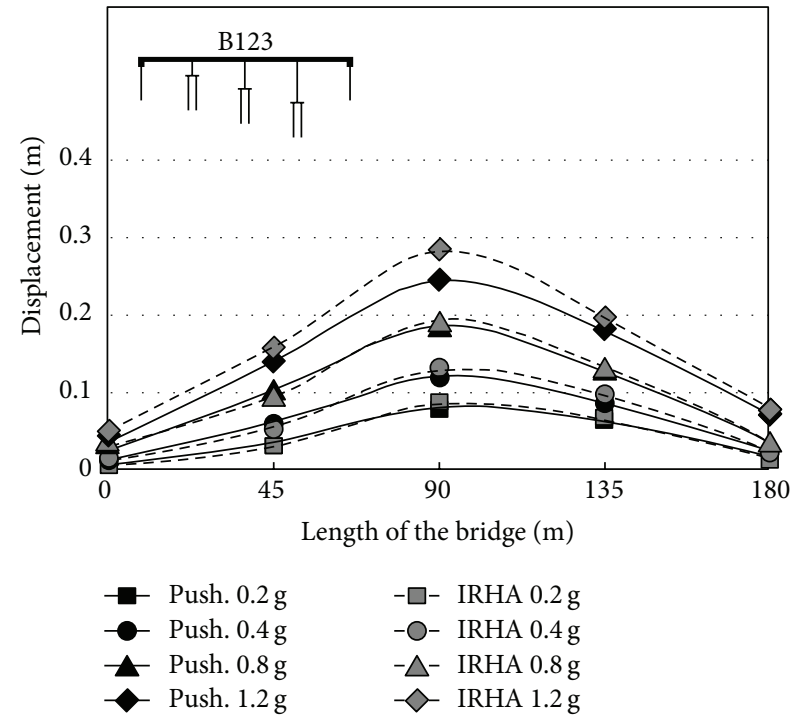

(b)

Figure 10: The deck displacement pattern of B222 and B123 under Tabas record (PGA $=0.2 \mathrm{~g}-1.2 \mathrm{~g}$ ). 

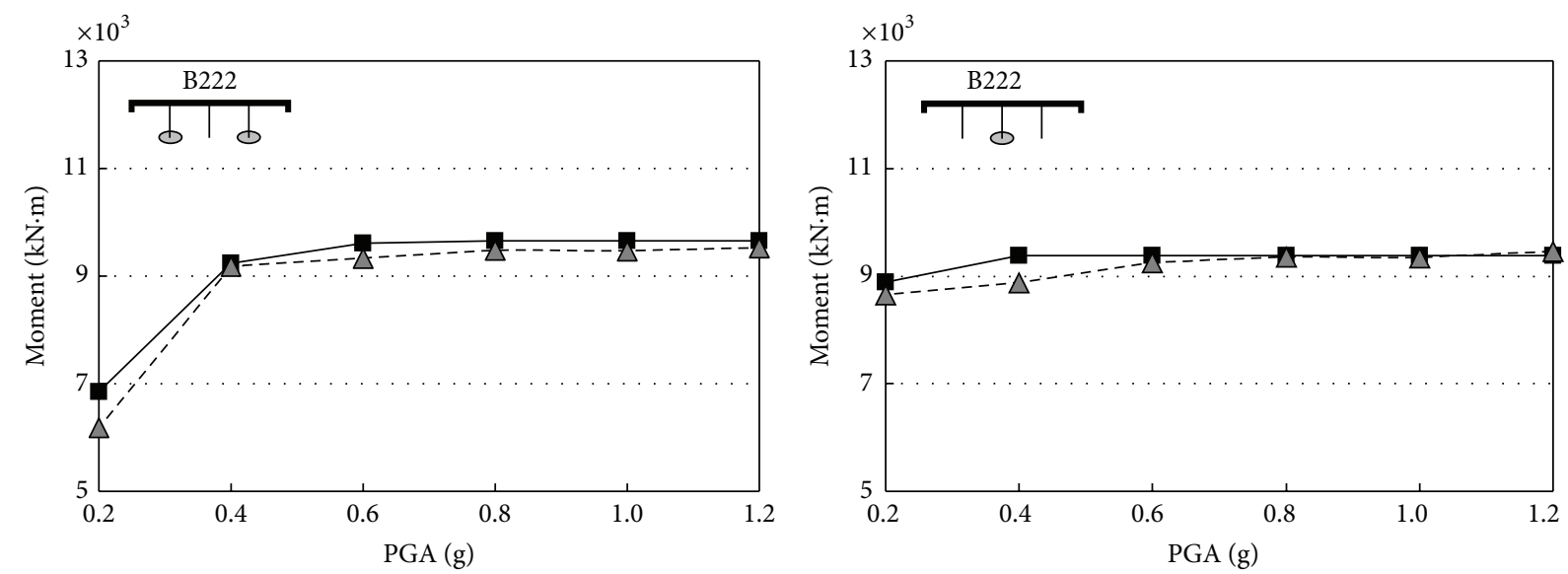

(a) Regular bridge (B222)
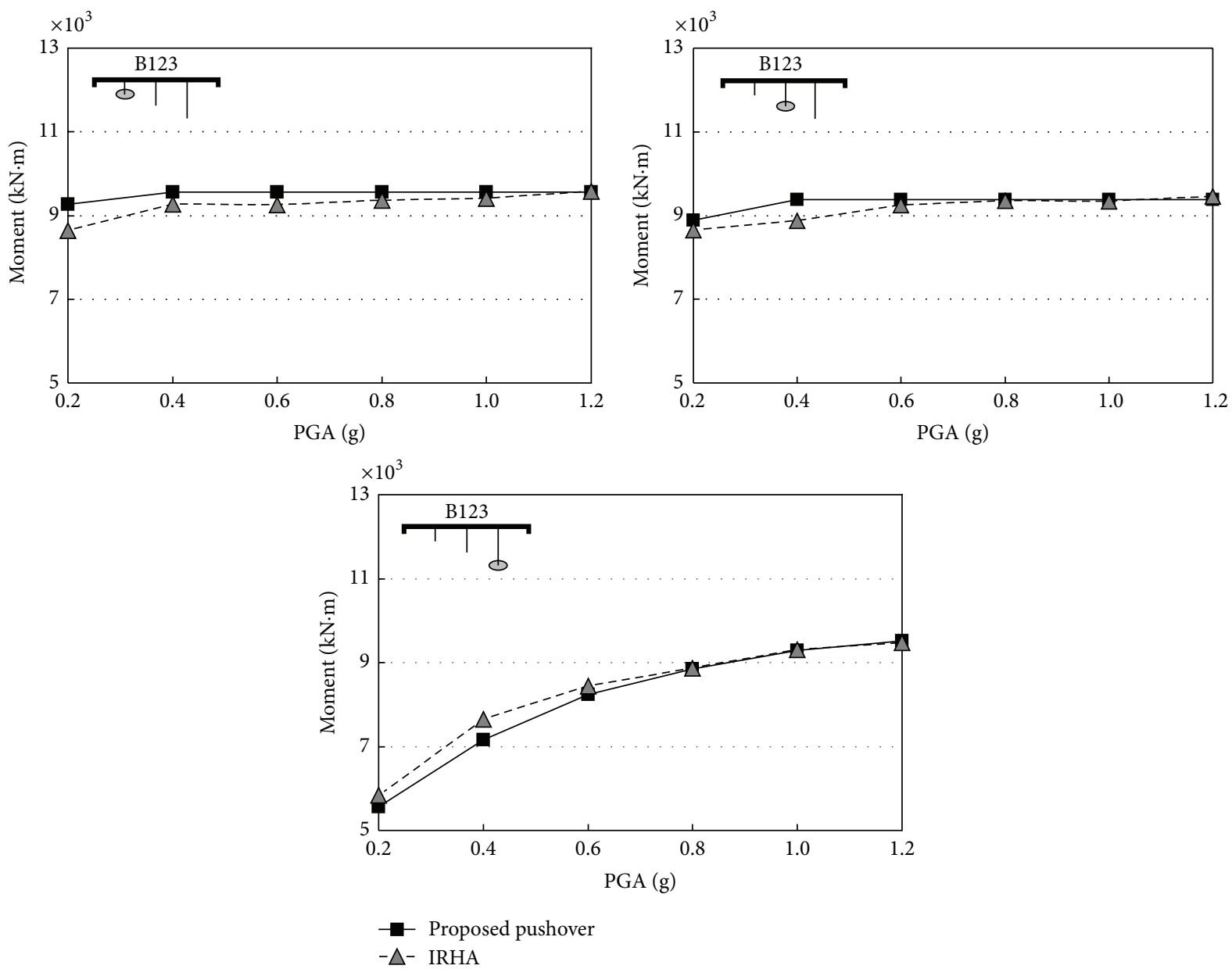

(b) Irregular bridge (B123)

FIGURE 11: Column base moments of B222 and B123 under Tabas record (PGA $=0.2 \mathrm{~g}-1.2 \mathrm{~g}$ ).

for the three modes increases as the columns yield. This increase is less significant for higher modes compared to the first mode. The proposed method has been capable of presenting accurate quantitative measure of the bridge modal characteristics.
4.4. Effect of Seismic Intensity on the Results. To investigate the effect of seismic intensity on the accuracy of the proposed method, an appropriate intensity measure should be selected. In this study, PGA is chosen as intensity measure since it has been identified as suitable for the seismic assessment 
TABLE 3: Modal characteristics of B123.

\begin{tabular}{lcccccccccc}
\hline \multirow{2}{*}{ Mode } & \multicolumn{2}{c}{ Initial state } & \multicolumn{2}{c}{ 1st yield $^{\mathrm{a}}$} & \multicolumn{2}{c}{ 2nd yield $^{\mathrm{a}}$} & \multicolumn{2}{c}{ 3rd yield $^{\mathrm{a}}$} & \multicolumn{2}{c}{ Ultimate state $^{2}$} \\
& $T(\mathrm{~s})^{\mathrm{b}}$ & $M(\%)^{\mathrm{c}}$ & $T(\mathrm{~s})$ & $M(\%)$ & $T(\mathrm{~s})$ & $M(\%)$ & $T(\mathrm{~s})$ & $M(\%)$ & $T(\mathrm{~s})$ & $M(\%)$ \\
\hline 1st & 0.751 & 69.2 & 1.295 & 78.4 & 1.375 & 79.6 & 2.198 & 85.4 & 3.134 \\
2nd & 0.408 & 2.3 & 0.567 & 0.1 & 0.594 & 0.3 & 0.961 & 4.0 & 1.392 \\
3rd & 0.272 & 24.6 & 0.353 & 19.9 & 0.367 & 18.6 & 0.476 & 8.9 & 0.623 & - \\
\hline
\end{tabular}

${ }^{\mathrm{a}} 1 \mathrm{st}$, 2nd, and 3rd yield: short, medium, and tall columns reaching their corresponding $\Delta_{y}$, respectively.

${ }^{\mathrm{b}} T$ is the period of vibration (in seconds).

${ }^{\mathrm{c}} M(\%)$ is the effective modal mass divided by the total mass of the structure (given in percentage).

of bridges [26]. Here, the PGA of Tabas record is selected and scaled to typical values in the range from $0.2 \mathrm{~g}$ to $1.2 \mathrm{~g}$. The records are then applied to one regular bridge (B222) and one irregular bridge (B123). Figure 10 shows the deck displacement pattern for different seismic intensities. It can be seen that the results of the proposed method are almost identical to IRHA results. Only for PGA of $1.2 \mathrm{~g}$, the proposed method underestimates the displacements of the two middle spans, whereas the displacements of the two end spans are still estimated properly. Figure 11 shows column base moments for different intensity levels. The proposed method has been able to estimate the moments very close to the IRHA results in all intensity levels. Therefore, it can be concluded that the intensity of the ground motion does not have a significant effect on the accuracy and robustness of the proposed method. Furthermore, the deformed shape of the bridge and the column base moments are very well captured for both regular and irregular bridges. Therefore, the bridge regularity does not affect the performance of the proposed procedure in different intensity levels.

\section{Conclusions}

An efficient nonlinear static procedure for the seismic assessment of integral bridges has been presented in this paper. The proposed method is basically a multimode adaptive capacity spectrum method with improvements in the assessment of capacity and demand curves. The proposed method employs incremental-iterative analysis and updates both capacity and demand curves at each load increment. The performance point is defined as the intersection of the two adaptive curves. The displacements and internal forces are then determined accordingly.

A parametric study has been conducted to evaluate the accuracy and suitability of the proposed method. The inelastic response history analysis has also been selected as the reference solution. Numerical results of the parametric study indicate that the proposed method estimates the displacement and force responses of the simulated bridges close to the results obtained by the reference solution. For most of the bridges investigated in this study, this difference is less than $25 \%$ for prediction of displacements. The results are more accurate for column moments with average difference of less than $10 \%$. Besides, the dispersion of results is low such that the maximum standard deviation is $17 \%$ for displacements and $7 \%$ for column moments. These values are considered quite acceptable compared to the values reported in the literature.
Numerical results also show that the regularity of the bridge has negligible effect on the accuracy of the proposed procedure. The proposed method has been able to predict both displacement and force responses of regular and irregular bridges with similar accuracy. Moreover, the intensity of the ground motion does not affect the accuracy of the proposed method in estimating the force response of the bridge. It is observed, however, that the difference between the displacement response of the proposed method and that of the reference solution slightly increases as the intensity of the ground motion increases. Nevertheless, this increase has not affected the overall accuracy and the proposed method performs satisfactorily for most intensity levels.

It is finally emphasized that the proposed procedure can also be utilized for other types of bridges with small adjustments. Besides, this method provides a robust tool for development of fragility curves and evaluation of the seismic performance of bridges.

\section{References}

[1] EC8-2, Eurocode 8: Design of structures for earthquake resistance-Part 2: Bridges, EN 1998-2, Comité Européen de Normalisation (CEN), Brussels, Belgium, 2005.

[2] Caltrans, Caltrans Seismic Design Criteria, Version 1.6, California Department of Transportation, Sacramento, Calif, USA, 2010.

[3] T. Isaković and M. Fischinger, "Higher modes in simplified inelastic seismic analysis of single column bent viaducts," Earthquake Engineering and Structural Dynamics, vol. 35, no. 1, pp. 95-114, 2006.

[4] S. A. Freeman, J. P. Nicoletti, and J. V. Tyrell, "Evaluations of existing buildings for seismic risk - a case study of Puget Sound Naval Shipyard, Bremerton, Washington," in Proceedings of the 1st US National Conference on Earthquake Engineering, Ann Arbor, Mich, USA, June 1975.

[5] P. Fajfar and P. Gašperšič, "The N2 method for the seismic damage analysis of RC buildings," Earthquake Engineering and Structural Dynamics, vol. 25, no. 1, pp. 31-46, 1996.

[6] A. M. Reinhorn, "Inelastic analysis techniques in seismic evaluations," in Proceedings of the International Workshop on Seismic Design Methodologies for the Next Generation of Codes, Bled, Slovenia, June 1997.

[7] G. M. de Rue, Nonlinear static procedure analysis of $3 D$ structures for design applications [M.S. thesis], State University of New York at Buffalo, Buffalo, NY, USA, 1998. 
[8] M. N. Aydinoğlu, "An incremental response spectrum analysis procedure based on inelastic spectral displacements for multimode seismic performance evaluation," Bulletin of Earthquake Engineering, vol. 1, no. 1, pp. 3-36, 2003.

[9] C. Casarotti and R. Pinho, "An adaptive capacity spectrum method for assessment of bridges subjected to earthquake action," Bulletin of Earthquake Engineering, vol. 5, no. 3, pp. 377390, 2007.

[10] R. Pinho, R. Monteiro, C. Casarotti, and R. Delgado, "Assessment of continuous span bridges through nonlinear static procedures," Earthquake Spectra, vol. 25, no. 1, pp. 143-159, 2009.

[11] OpenSees, Open System For Earthquake Engineering Simulation, Pacific Earthquake Engineering Research Center (PEER), 2000, http://opensees.berkeley.edu.

[12] J. M. Ortega and W. C. Rheinboldt, Iterative Solution of Nonlinear Equations in Several Variables, Academic Press, New York, NY, USA, 1970.

[13] T. Takeda, M. A. Sozen, and N. N. Nielsen, "Reinforced concrete response to simulated earthquakes," Journal of the Structural Division, vol. 96, no. 12, pp. 2557-2573, 1970.

[14] M. J. Kowalsky, "Deformation limit states for circular reinforced concrete bridge columns," Journal of Structural Engineering, vol. 126, no. 8, pp. 869-878, 2000.

[15] A. Mwafy, O. Kwon, and A. S. Elnashai, "Seismic assessment of an existing nonseismically designed major bridge-abutmentfoundation system," Engineering Structures, vol. 32, pp. 21922209, 2010.

[16] AASHTO, AASHTO LRFD Bridge Design Specifications, American Association of State Highway and Transportation Officials, Washington, DC, USA, 4th edition, 2007.

[17] J. B. Mander, M. J. N. Priestley, and R. Park, "Theoretical stress-strain model for confined concrete," Journal of Structural Engineering, vol. 114, no. 8, pp. 1804-1826, 1988.

[18] M. Menegotto and P. E. Pinto, "Method of analysis for cyclically loaded R.C. plane frames including changes in geometry and non-elastic behaviour of elements under combined normal force and bending," in IABSE Symposium: Resistance and Ultimate Deformability of Structures Acted on By Well Defined Repeated Loads, 1973.

[19] API, Recommended Practice For Planning, Designing and Constructing Fixed Offshore Platforms-Working Stress Design (RP 2A-WSD), American Petroleum Institute, Washington, DC, USA, 21st edition, 2000.

[20] R. K. Goel and A. K. Chopra, "Evaluation of bridge abutment capacity and stiffness during earthquakes," Earthquake Spectra, vol. 13, no. 1, pp. 1-23, 1997.

[21] PEER, PEER Strong Motion Database, Pacific Earthquake Engineering Research Center, 2000, http://peer.berkeley.edu/.

[22] K-NET, Kyoshin Strong-Motion Seismograph Network, National Research Institute for Earth Science and Disaster Prevention (NIED), 1996, http://www.kyoshin.bosai.go.jp/.

[23] M. H. DeGroot, Probability and Statistics, Addison-Wesley, Reading, Mass, USA, 2nd edition, 1986.

[24] G. M. Calvi, A. S. Elnashai, and A. Pavese, "Influence of regularity on the seismic response of RC bridges," in Proceedings of the 2nd International Workshop on Seismic Design and Retrofitting of RC Bridges, Queenstown, New Zealand, August 1994.

[25] R. Akbari and S. Maalek, "Adequacy of the seismic analysis methods for single-column-bent viaducts considering regularity and higher modes effects," Journal of Vibration and Control, vol. 16 , no. 6, pp. 827-852, 2010.
[26] J. E. Padgett, B. G. Nielson, and R. DesRoches, "Selection of optimal intensity measures in probabilistic seismic demand models of highway bridge portfolios," Earthquake Engineering and Structural Dynamics, vol. 37, no. 5, pp. 711-725, 2008. 

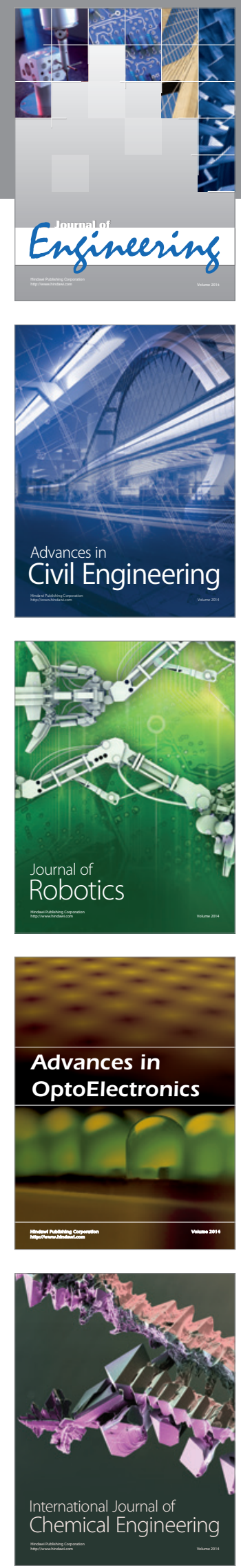

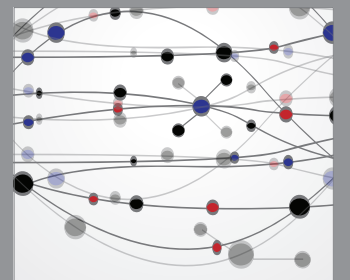

The Scientific World Journal
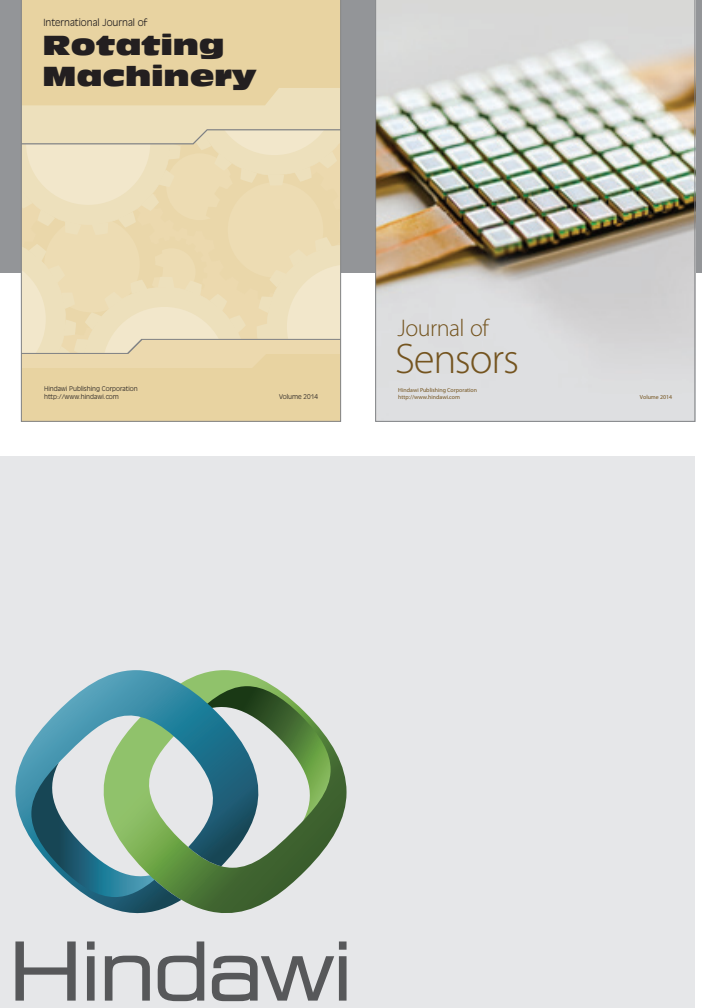

Submit your manuscripts at http://www.hindawi.com
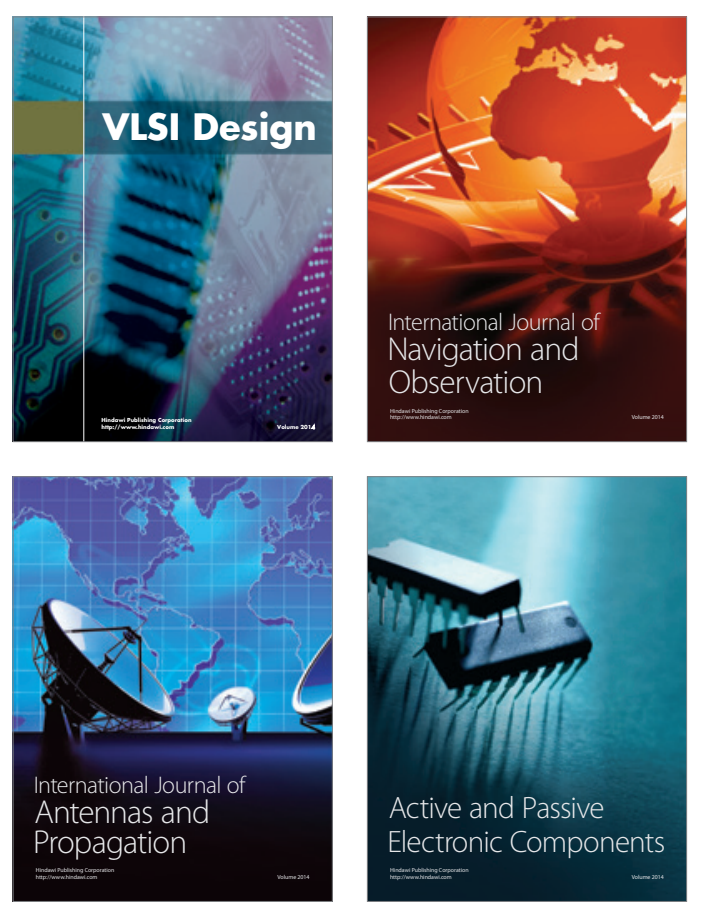
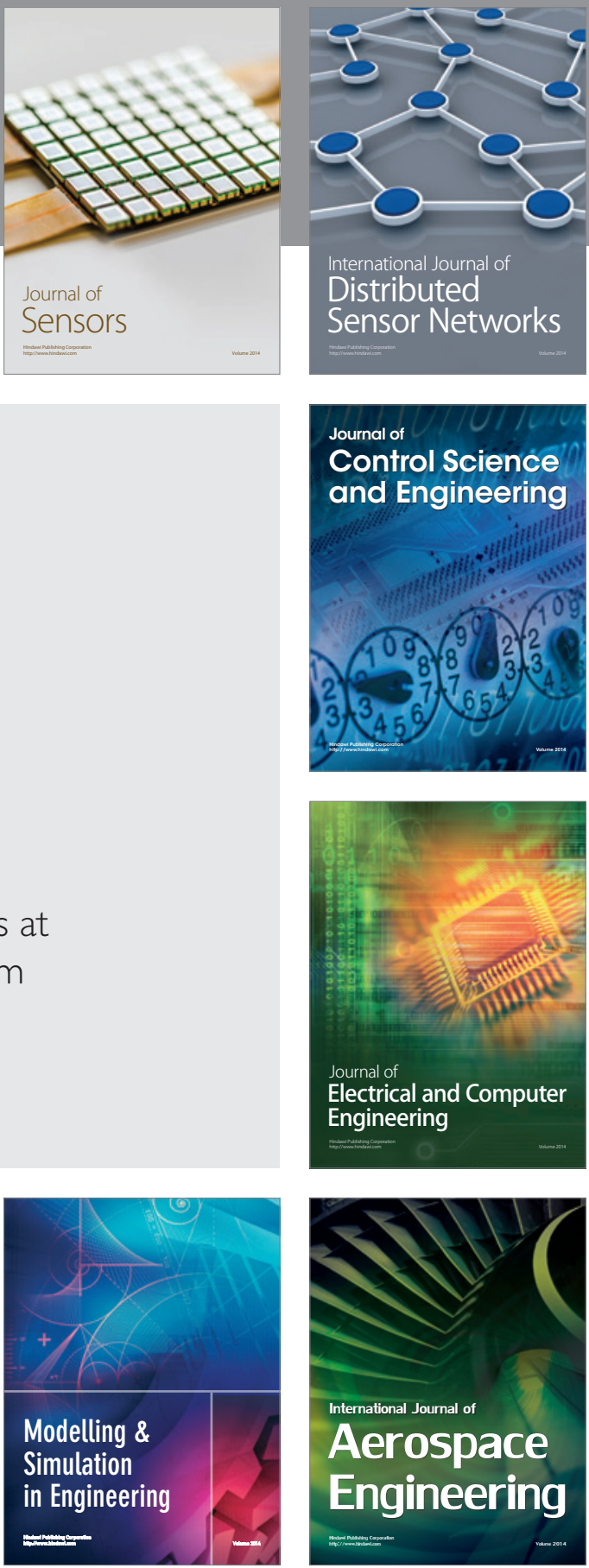

Journal of

Control Science

and Engineering
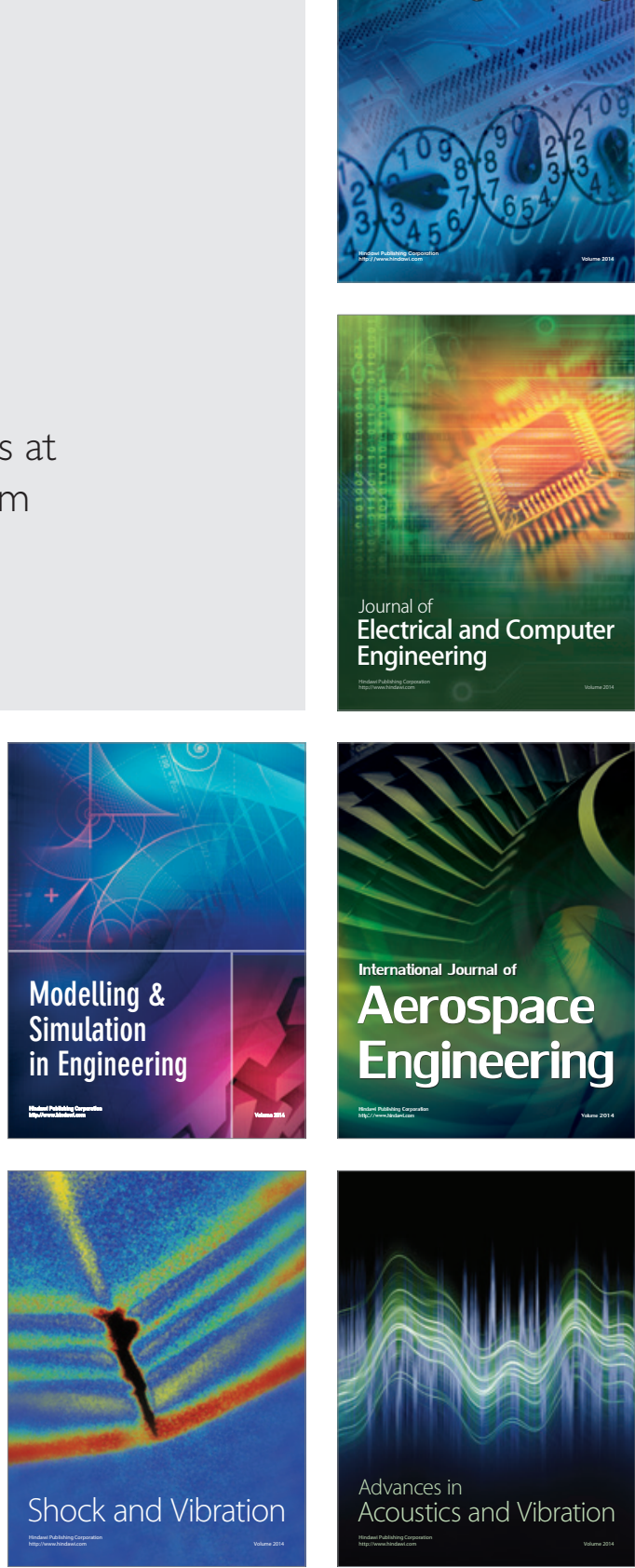